\title{
Emergent operation of an extensive pulmonary damage after thoracal gunshot assault
}

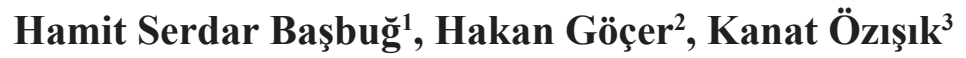

\footnotetext{
1) Kafkas University Faculty of Medicine, Department of Cardiovascular Surgery, Assoc. Dr., Kars, Turkey

${ }^{2)}$ Kafkas University Faculty of Medicine, Department of Cardiovascular Surgery, MD, Kars, Turkey

${ }^{3)}$ Kafkas University Faculty of Medicine, Department of Cardiovascular Surgery, Prof. Dr., Kars, Turkey
}

\begin{abstract}
Transthoracic gunshot injuries acquire immediate intervention with a correct approach as they have high mortality rates. The high mortality mainly depends on the presence of a probable concomitant injury of the cardiac, pulmonary and major thoracal vascular structures. In this case report, the emergent surgical management of a young female referred with a thoracal gunshot wound causing a massive pulmonary destruction is presented.
\end{abstract}

Keywords: Firearms; thorax; lung injury 


\section{Introduction}

Thoracic gunshot injuries are associated with high mortality due to concomitant pulmonary, cardiac or major vascular injuries. ${ }^{1}$ The treatment of hemodynamically unstable patients with thoracic gunshot wounds is emergent due to major cardiac or vascular injuries. These patients should immediately proceed to the operating room..$^{2}$ In hemodynamically stable patients, diagnostic tests are needed before urgent transfer to the operation. ${ }^{3}$ In this paper, the emergent surgical management of a young woman with a transthoracic gunshot wound was presented. This case is diversified from others attributing to the presence of a pulmonary damage with a suspicious cardiac injury.

\section{Case Report}

A 22-year-old female referred with a thoracic gunshot wound. She was conscious with a blood pressure of $80 / 50 \mathrm{mmHg}$ and heart rate of $124 \mathrm{bpm}$. She had firearm bullet entry wound just above her left nipple and an exit wound on her left posterior axillary line below the

Figure 1. Morphological view of the penetrating firearm wound. Note the contact muzzle stamp around the bullet entry hole.

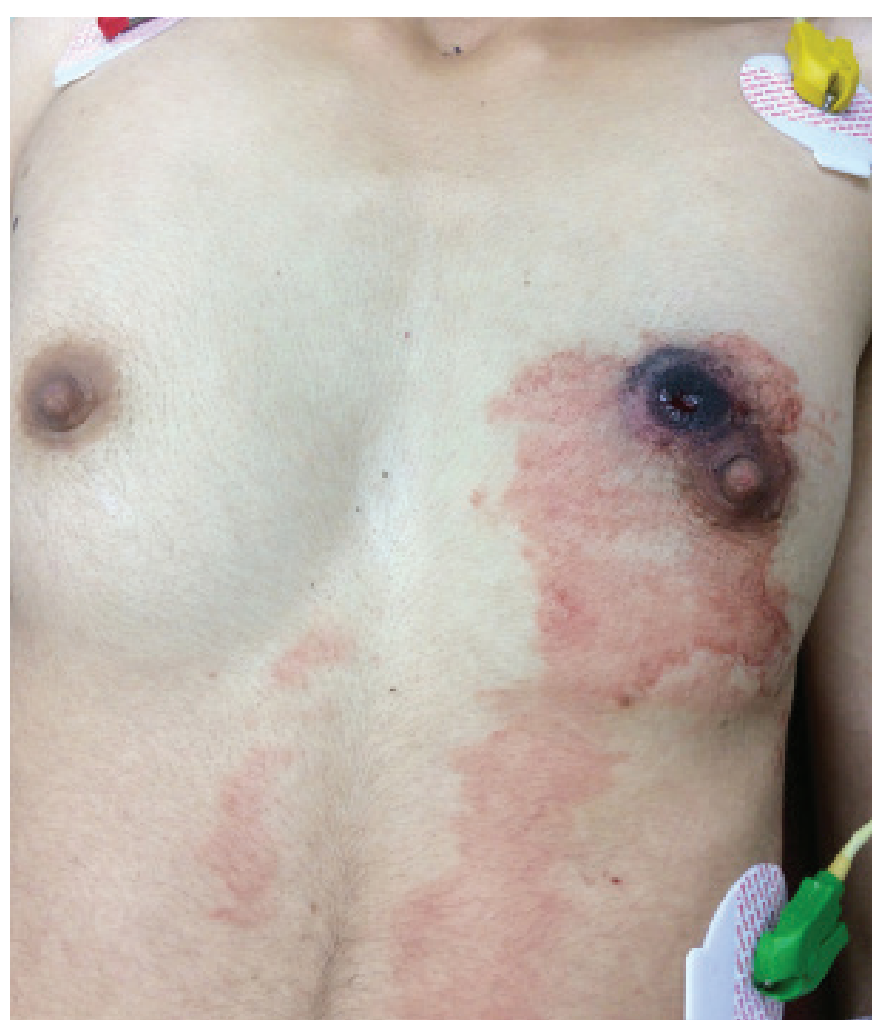

sixth intercostal space. Physical examination of the entry wound revealed a contact muzzle stamp over the nipple (Figure 1). Posteriorly, there was a lateral bullet exit lesion between the sixth intercostal space and the fractured seventh rib. The Computerized Tomography (CT) Angiography of the thorax demonstrated the lack of great vessel injury and the presence of a massive left hemothorax consistent with the left pulmonary parenchymal injury (Figure 1). There was an interesting patchy opaque extravasation around the pericardium near the cardiac apex which might be related to a cardiac injury (Figure 2). Thus, the patient was taken to the operating room urgently. Following a median sternotomy, the pericardium was dissected $1 \mathrm{~cm}$ long to explore and see the pericardial

Figure 2. Computerized Tomography (CT) Angiography of the thorax demonstrates the presence of a massive left hemothorax with a contrast extravasation consistent with the left pulmonary parenchymal injury (A). The suspicious view in the CT Angiography implicating a cardiac injury (B).

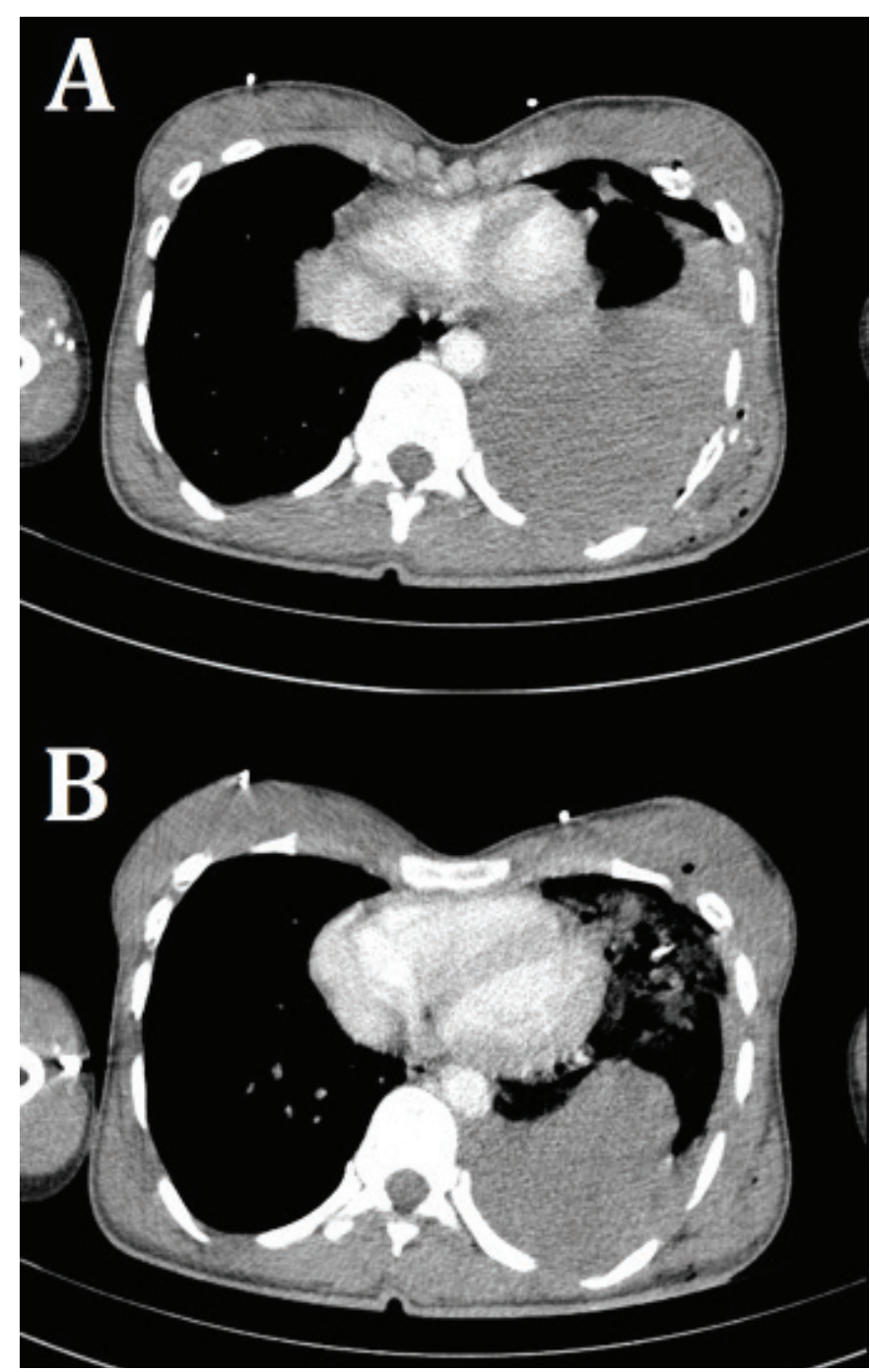


aspirate. There was no hemopericardium consistent with a cardiac involvement that was suspected by the Figure 1. Left pleura was then widely opened beneath the sternum and $1200 \mathrm{ml}$ of blood was aspirated from the left thorax. Upon examination of the left lung, the superior lobe was seriously injured. The parenchymal laceration was repaired with a 4-0 polypropylene by double running stitch (Figure 1). Near the bullet exit site over the inferior lobe, there was another parenchymal laceration which was also repaired with the same suturing technique. No postoperative complication happened.

\section{Discussion}

Advances in prehospital care systems enabled shorter delivery times for the penetrating trauma patients to the hospitals. "Scoop and run" strategy have replaced the older "stay and play" manner. This resulted in more trauma victims become more able to reach the emergency departments in extremis. ${ }^{4}$ Despite this advance in improvement in the transportation of the casualties to the hospital, overall survival after transthoracic gunshot injuries has not improved satisfactorily depending on the publications between 1966 and 2012. ${ }^{1}$ From Bradley ${ }^{5}$ who reported the first case series in 1966 with a $20 \%$ of mortality, up to Okeye et al. ${ }^{1}$ who declared an overall mortality rate of $78 \%$, the survival after transthoracic gunshot wounds is still inefficiently low.

Transthoracic gunshot wounds are almost always associated with a hemodynamic compromise and require urgent appropriate intervention. ${ }^{6}$ However, hemodynam-

Figure 3. The intraoperative image is demonstrating the pulmonary parenchymal destruction. Note the hemorrhage through the laceration site.

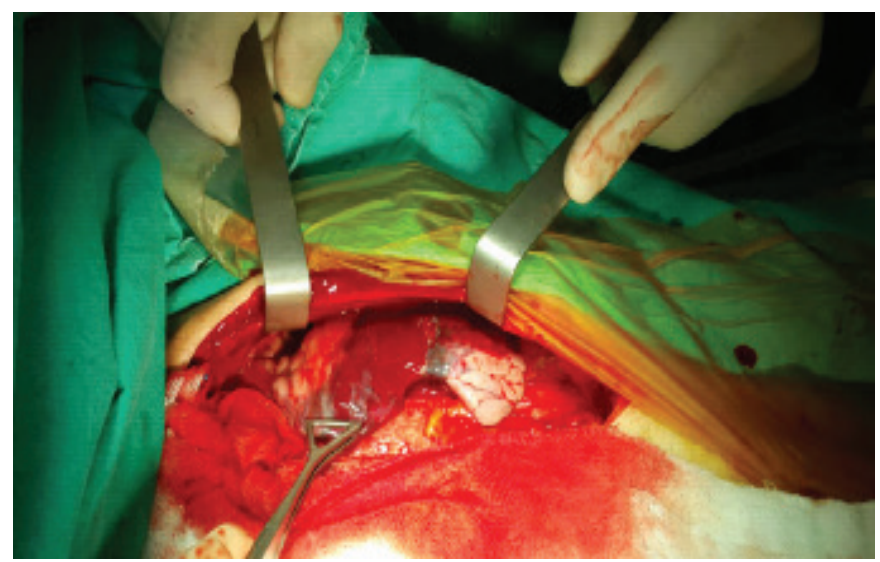

ically stable patients with transthoracic gunshot wounds would also have a potential risk for significant occult injury. ${ }^{7}$ Degiannis et al. ${ }^{8}$ reported $42 \%$ occult injuries among stable patients. Moreover, Richardson et al. ${ }^{9}$ observed occult injury in $63 \%$ of their patients who were initially stable. Thus, the traditional preoperative diagnostic tests in these instances become more crucial to determine the severity of the injury as well as to exclude a significant occult injury among the asymptomatic or less symptomatic cases. Intravenous contrast CT imaging is generally used for visualization the missile tract as well as to evaluate the vascular integrity. ${ }^{10}$ The use of CT-imaging as a screening tool is generally sufficient to rule out significant thoracic and mediastinal injury. ${ }^{11}$

The operative approach in transthoracic penetrating trauma patients depends on the hemodynamic condition of the patient and the injury site. ${ }^{12}$ In a hemodynamically stable patient with a mediastinal penetrating injury, the incision should be tailored meticulously. The majority of cardiac and thoracic injuries can comfortably be handled with a median sternotomy. ${ }^{13}$

However, for patients who arrived in extremis, lateral thoracotomy and aortic cross-clamping may be suitable to control the mediastinal bleeding rapidly. ${ }^{14}$ The surgical approach must be directed to the optimal exposure and easiest access. Injuries of the structures located in the posterior mediastinum including the thoracic esophagus, descending aorta, distal tracheobronchial structures need lateral thoracotomy while the cardiac and ascend-

Figure 4. The intraoperative image is demonstrating the pulmonary parenchymal repair. Note the hemorrhage was stopped.

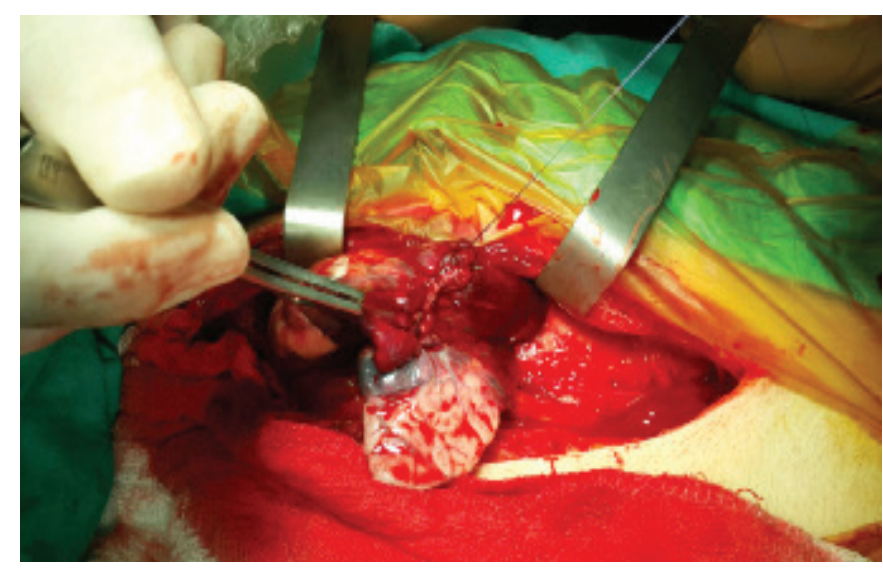


ing aorta injuries need median sternotomy. ${ }^{1}$ In this case, a median sternotomy was preferred to evaluate the suspicious cardiac involvement that was seen on CT image (Figure 3). CT image revealed a suspicious contrast extravasation that may implicate a possible apical involvement as the bullet was glanced off. Upon performing a tiny pericardial incision, no pericardial blood was seen. By excluding the cardiac involvement, the left lung was

\section{References}

1. Okoye OT, Talving P, Teixeira PG, Chervonski M, Smith JA, Inaba K, et al. Transmediastinal gunshot wounds in a mature trauma centre: Changing perspectives. Injury 2013;44(9):1198-203.

2. Stassen NA, Lukan JK, Spain DA, Miller FB, Carrillo EH, Richardson JD. Reevaluation of diagnostic procedures for transmediastinal gunshot wounds. J Trauma 2002;53(4):635-8.

3. Cornwell EE, Kennedy F, Ayad IA, Berne TV, Velmahos G, Asensio J, et al. Transmediastinal gunshot wounds: a reconsideration of the role of aortography. Arch Surg 1996;131(9):949-53.

4. Smith RM, Conn AK. Prehospital care-scoop and run or stay and play? Injury 2009;40(Suppl. 4):S23-6.

5. Bradley MN. Transmediastinal wounds. Am Surg 1966;32:847-52.

6. Kerimoğlu B, Köse S, Özışık K, Ertürk M, Koşar A, Orhan G. Yüksek hızlı ateşli silahlarla oluşan toraks yaralanmaları. T Klin J Med Sci 2001;21(4):249-52.

7. Nagy KK, Roberts RR, Smith RF, Joseph KT, An GC, Bokhari F, et al. Transmediastinal gunshot wounds: are "stable" patients really stable? World J Surg 2002;26:1247-50

8. Degiannis E, Benn CA, Leandros E, Goosen J, Boffard K, Saadia R. assessed and repaired through the sternotomy easily (Figure 4) and the drain tubes were successfully placed.

In conclusion, transthoracic firearm injuries are almost always associated with hemodynamic compromise and require rapid and appropriate resuscitative surgical exploration. Thus, depending on the injured structures and vital status of the patient, correct approach should be tailored in these life-threatening injuries.

Transmediastinal gunshot injuries. Surgery 2000;128:54-8.

9. Richardson JD, Flint LM, Snow NJ, Gray Jr LA, Trinkle JK. Management of transmediastinal gunshot wounds. Surgery 1981;90:671-6.

10. Grossman MD, May AK, Schwab CW, Reilly PM, McMahon DJ, Rotondo $\mathrm{M}$, et al. Determining anatomic injury with computed tomography in selected torso gunshot wounds. J Trauma 1998;45:446-56.

11. Hanpeter DE, Demetriades D, Asensio JA, Berne TV, Velmahos G, Murray $\mathrm{J}$. Helical computed tomographic scan in the evaluation of mediastinal gunshot wounds. J Trauma 2000;49:689-94.

12. Peper WA, Obeid FN, Horst HM, Bivins BA. Penetrating injuries of the mediastinum. Am Surg 1986;52:359-65.

13. O'Connor JV, Scalea TM. Penetrating thoracic great vessel injury: impact of admission hemodynamics and preoperative imaging. J Trauma 2010;68:834-7

14. Working Group, Ad Hoc Subcommittee on Outcomes, American College of Surgeons. Committee on trauma, practice management guidelines for emergency department thoracotomy. working group, ad hoc subcommittee on outcomes, American college of surgeons-committee on trauma. J Am Coll Surg 2001;193:303-9.

Received: 19/06/2017

Accepted: 21/11/2017

Published: 15/03/2017

Disclosure and conflicts of interest:

Conflicts of interest were not reported.

\section{Corresponding author:}

Hamit Serdar Başbuğ

Mail: s_basbug@hotmail.com 